
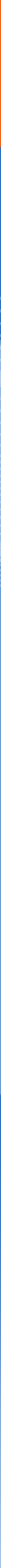


\section{CON DENTS}

Foreword

Introduction

Summary of Key Findings

The Journey to AI Maturity

The Al Ethics Debate

Conclusion

About Infosys
4

5

7

8

13

17

19 
Artificial Intelligence (Al) is reshaping the human journey. It is becoming increasingly part of every aspect of our lives, from simple things such as the way we shop and drive, to more fundamental things like how our homes, automobiles and offices amplify us. These elicit a mixture of emotions, from fascination to fear, from wonder to worry. For us, as business leaders, the potential to leverage Al to transform our businesses, bringing radical cost reductions and efficiencies while opening up entirely new kinds of opportunities, is truly exciting. As managers and employers, as citizens in our communities, we bear the great responsibility that comes with transformation, to ensure we are driving a purposeful approach to Al.

And yet, we are only just beginning to see the massive potential of Al. Since humanity's earliest days, technology has been a great enabling force that amplifies and empowers people, improving our quality of life, unlocking new opportunities, enhancing our creativity and equalizing the playing field for all. Al and automation technologies are taking this to a whole new level, enabling us to do more than we could have ever imagined. As intelligent systems take over more of the known, well-defined work, we will be called to exercise our human creativity and ingenuity to find new problems and opportunities and create new kinds of products, experiences, and value that do not yet exist.

The story of technological disruption and human transcendence continues to play out today, though the pace of change is only accelerating. Therefore, we need to rethink that which makes us fundamentally human - our ability to learn. We, as humans, have always been able to adapt to dramatic changes in our world because we have evolved the way we learn alongside our increasingly powerful technologies. We must now think beyond how we've been approaching our education, to recast it as a holistic, continuous and lifelong process of learning — one in which problem-finding is as important as problemsolving, and digital literacy is taken as seriously as language literacy.

Moreover, we must not lose sight of the values and ethics involved in this journey, particularly as it pertains to business. Standards must be developed and governed, and engineers must realize that what they build is not without consequence. Leaders have a great responsibility today, to steer their businesses and extended organizations purposefully through these extraordinary times.

Infosys, for its part, set out to understand more about current levels of Al adoption in enterprise; decisionmaker perspectives on Al technologies; and future market disruption. In particular, we looked at job skills and ethics, market maturity and growth rate expectations. We believe that with greater understanding, we can further explore the opportunities and challenges that businesses face as they look to implement Al and do more to realize its potential. We can do this in a purposeful way - one that amplifies all that is possible, even beyond what we can imagine today, in our individual and collective human potential.

\section{Dr. Vishal Sikka, CEO, Infosys}




\section{INTRODUCTION}

The way we interact, the way we make decisions and the way we learn are all being shaped and influenced by the rapidly developing and increasingly accessible computing technology around us. Nowhere is this more prevalent than in the use and adoption of Al.

The ever-expanding presence of Al in our daily lives evokes a complex emotional response, from fascination and curiosity to fear and anxiety. But are these concerns justified, given the vast array of positive use cases of Al that will define the future? For employees and customers, what are the benefits that can be harnessed from Al for their advantage and, quite possibly, for the wider world? For organizations, especially those in the midst of considering their own adoption of $\mathrm{Al}$, the challenge lies in balancing risk and reward across both the workforce and the operations of the business.

In the face of such questions, Infosys commissioned independent market research company Vanson Bourne to investigate the approach and attitudes that senior decision-makers in large organizations have towards Al technology and how they see the future application and development of $\mathrm{Al}$ in their industries. The study also sought to measure and score organizational maturity, to create an index and set of profiles for the countries and industries examined.
There is no precise definition for Artificial Intelligence (Al) as experts throughout the field disagree on the exact wording. Marvin Minsky, the renowned MIT professor, defined Al as "the science of making machines do those things that would be considered intelligent if they were done by people."This is a pragmatic definition, still valid today. In laymen's terms, Al is any activity that used to only be done via human intelligence that now can be executed by a computer. Some of the most powerful Al examples today include visual perception, speech recognition, machine learning, decision-making and natural language processing. These functions used to require an immense number of man-hours but can now be done in a fraction of the time and with a much higher degree of accuracy than before. As time moves forward and computers develop more processing power and pervasiveness, Al will develop a larger set of capabilities for addressing an expanding array of use cases - a phenomenon known as the "Al effect". 
For the purposes of this research, Al was defined as an area of computer science that emphasizes the creation of intelligent machines that work and react like humans. Some of the activities that computers with Al are designed for include image and speech recognition, learning, planning and problem-solving. Examples of applied Al technologies include (but are not limited to): machine learning, deep learning, predictive/prescriptive analytics, virtual agent and natural language understanding (avatar) technologies (Siri, Alexa, Google Home, Amelia etc.)

The research results reinforce the notion that Al will have a profound, disruptive effect on global business and society, and underscore the importance of developing and implementing a holistic Al strategy.

In undertaking this study, we sought to better understand both immediate and longer-term perceptions of Al and its role in individual businesses and in wider society. Respondents were asked to provide guidance on the expected contribution that Al would make to revenues, productivity and business rationalization, as well as to business expansion. Respondents were also questioned on the ethical issues related to Al. This was to build understanding of whether ethical considerations were already part of their corporate Al roadmaps. From this, we sought to evaluate the extent to which human disruption associated with Al adoption was being considered by enterprise decision-makers.
The study looked at three key themes in relation to $\mathrm{Al}$ adoption and use:

- How could organizations assess their use of Al technologies to develop a strategic plan?

- How could organizations address the ethical issues behind the use of Al?

- What is expected of future generations of the workforce, in terms of skills and flexibility, to succeed in a world of Al?

This document and the results aim to define what constitutes a successful, Al-mature organization and demonstrate what others can learn in order to continue their own Al adoption journey. 


\section{SUMMARY OF KEY FINDINGS}
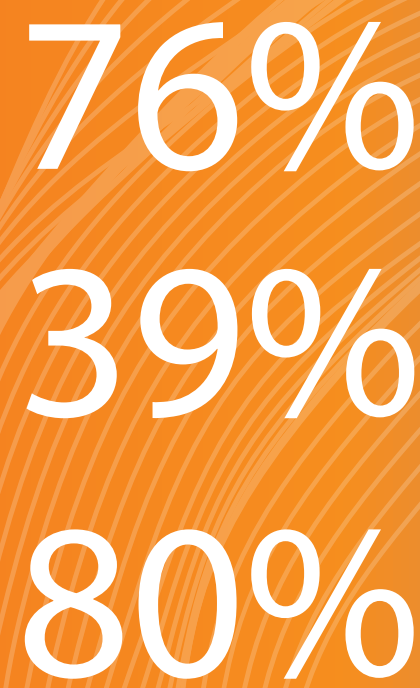

Three-quarters of senior decision-makers agree that Al is fundamental to the sucecess of their organization's strategy

By 2020, those currently or planning to use AI technology anticipate a $39 \%$ boost to their organization's revenue, on average

Eight in 10 organizations that have replaced, or plan to replace, roles with technology will retrain or redeploy those who are displaced
Organizations have been using Al for two years on average, but they don't expect to hit "mature" adoption for at least another three years. Meanwhile, only 25\% state that they have Al technologies fully deployed and working as expected. Of those that use it, only 10\% believe they are fully maximizing the current available benefits of $\mathrm{Al}$.

However, over six in 10 (64\%) believe the future growth of their organization is dependent upon large-scale Al adoption. Over half (53\%) believe ethical concerns stop Al from being as effective as it can be. The vast majority believe employees (90\%) and customers (88\%) face concerns about the adoption of Al.

Nonetheless, the majority (71\%) of respondents believe that $\mathrm{Al}$ is "inevitable" and will be disruptive. Given this perceived inevitability, it is concerning that just over a third (36\%) believe that their organizations have fully considered the ethical issues relating to the use of Al. 


\section{THE NOURNEYTO AI MATURITY}

In an ever-changing, increasingly digital world, whether respondents' organizations are focused on strategies to improve the customer experience (46\%) or to develop new products and services (43\%), the vast majority (76\%) believe that Al is fundamental to the success of their organization's strategy.

Only a quarter (25\%) have fully deployed Al technology that is delivering up to expectations. Around four in 10 respondents believe that the time to implement, ease of use and the interoperability with other systems and platforms are areas of $\mathrm{Al}$ that require the most improvement before it can be effective in their organizations. For many, there is a long journey ahead, with most being somewhere en route. The bad news

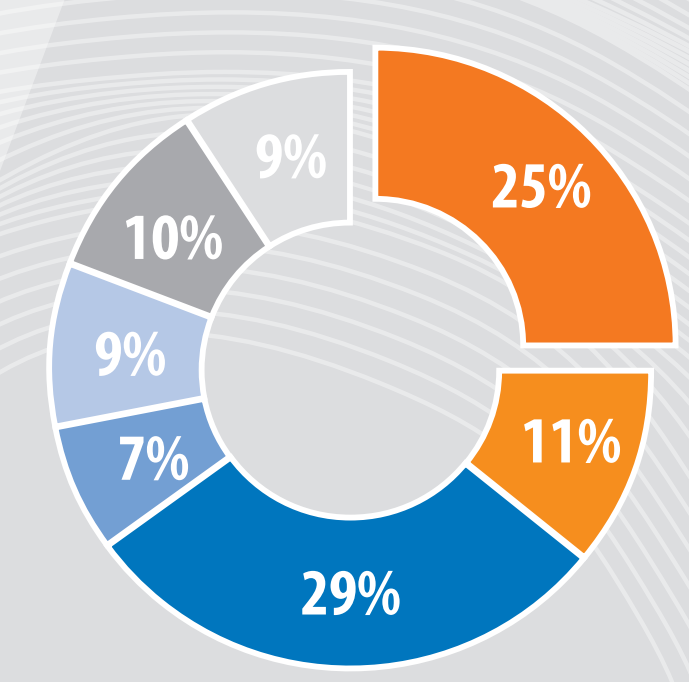

for the minority (9\%) with no intention to deploy $\mathrm{Al}$ is that they are at risk of being left behind.

What are the main Al technologies set for deployment in respondents' organizations, either now or in the future? Around two-thirds (65\%) say big data automation, and over half are looking at predictive analytics (54\%) or machine learning (51\%). Significant numbers have already, or are planning to, deploy expert systems (44\%) or neural networks (31\%).

Multiple forces are encouraging deployment. Of those whose organizations have deployed Al, they are commonly driven by a desire to harness competitive advantage (28\%) or are being led from an executive level (25\%).

Figure 1: "How would you rate your organization's current experience in terms of its implementation and use of Al technologies?", all respondents $(1,600)$

Fully deployed and they are working as expected

Fully deployed but they are not delivering to expectations

Partially deployed and they are working as expected

Partially deployed but they are not delivering to expectations

Limited deployment, results unknown

No deployment but we plan to in the future

No plans to deploy 
Figure 2: "How is your organization preparing for Al deployment and use?", all respondents $(1,600)$

Investing in supporting IT infrastructure

Developing knowledge/skills

Using external support to assist with planning

\section{Building Al into company ethos}

Using external support for knowledge gathering

Gathering feedback from customers

Assessing competitor/industry approach

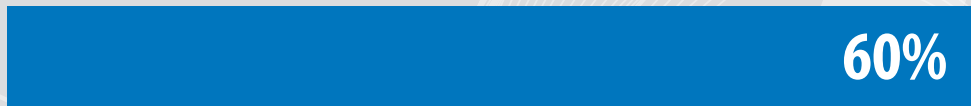

\section{$53 \%$}

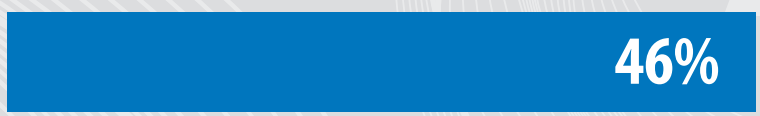

\section{$43 \%$}

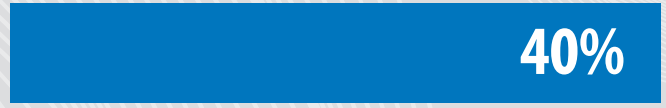

\section{$32 \%$}

\section{$25 \%$}

\section{Preparing for Al}

Respondents' organizations are preparing for Al deployment in several ways. Most commonly, this involves getting the foundations in place first by investing in supporting IT infrastructure (60\%) and developing knowledge/skills (53\%). Alongside this, many organizations recognize the value of outside specialist help - whether it is to assist with planning (46\%) or for knowledge gathering (40\%).

\section{Application within the business}

Reflecting the high value that most respondents' organizations place upon Al, an array of departments are already actively using it. The majority (69\%) report that IT is using Al. While this was broadly expected, adoption does not stop there. For around three in 10, operations (34\%), business development (33\%) and marketing (29\%) are all open to the use of AI. IT systems and security (54\%), data analytics (43\%) and customer service (43\%) are just a few of the many areas where $\mathrm{Al}$ is being considered for future deployment. On average, respondents' organizations that have fully, or partially, deployed Al-based technologies have invested $\$ 6.7$ million in them in the last year. 


\section{The Al maturity index methodology}

In order to add greater context to the investigation of the opportunities and challenges faced by organizations in adopting Al, a maturity index was created. This index defines five key maturity groups, highlighting the stages in the journey towards more effective uses of Al technologies.

At the very beginning of designing the research from which this report is based, a series of questions were developed to measure and score organizational maturity. The answers for these questions were assigned scores, and each respondent was given a total score across all areas.

Based on the score that they achieved, respondents were placed into one of five groups reflecting their organizations' Al maturity:
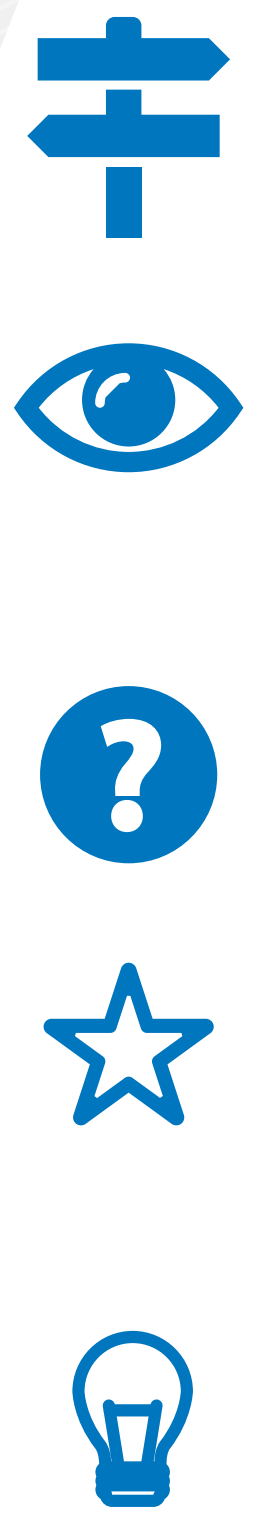

Skeptics (Maturity score: 0-19 percent) represent a small but significant group within the study. These organizations are least mature when it comes to Al, with no current deployment of such technologies and no plans to do so in the near future. These organizations tend to lack Alrelated skills and do not see a strong link between Al's adoption and the success of their strategy.

Watchers (Maturity score: 20-39 percent) made up of around a fifth of respondents' organizations. Here, partial deployment of Al has begun, but things remain in the very early learning stages of its use. Al skills are lower, and as such, many preparatory or supporting activities for Al are planned for the longer term. Nevertheless, the link between Al and strategy success is being recognized.

Explorers (Maturity score: 40-59 percent) are the most common group. Their partial deployments of Al are proving their value, and there is a desire to expand further. Al related skill levels are on the increase and more initiatives to support Al are on the horizon for the coming 12 months.

Rising Stars (Maturity score: 60-79 percent) are organizations that are taking the leap to a more widespread deployment of Al throughout the business. There is more work to do in order to maximize the benefits but initial successes are aided by a wider presence of Al-related skills and an increasing number of supporting activities. Al is seen as key to the organization's strategic success.

Visionaries (Maturity score: $\mathbf{8 0 - 1 0 0 ~ p e r c e n t ) ~ a r e ~ t h e ~ t r u e ~ A l ~ l e a d e r s . ~ T h i s ~ s m a l l ~ g r o u p ~}$ of organizations have already successfully deployed Al throughout their businesses and are reaping the benefits. Al-related skill levels are high and opening doors to a greater number of Al technologies and opportunities. Al is central to the success of their future strategies. 


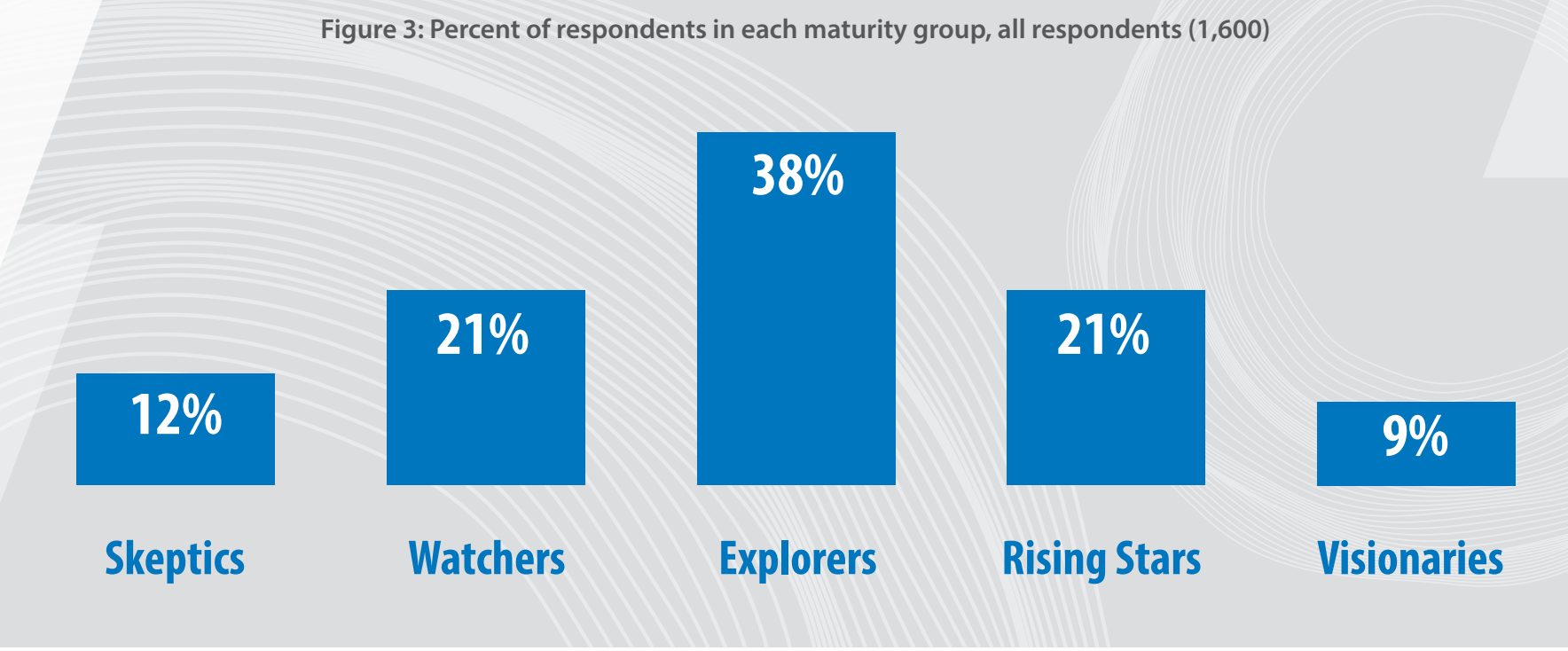

\section{Al maturity groups}

The index shows us that at this point in the Al journey, the profile of the largest group is that of the explorer those actively participating in probing, trying and learning about Al in real-world scenarios including deployments.

\section{A deeper look at Al maturity levels by country}

China and India head the maturity scoring by country, a trend replicated elsewhere in the research when

respondents were answering questions about the level of progress and adoption of Al. This is potentially due to both countries having fewer legacy systems and business processes to contend with, making Al adoption and integration easier to accomplish.

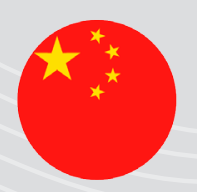

CHINA
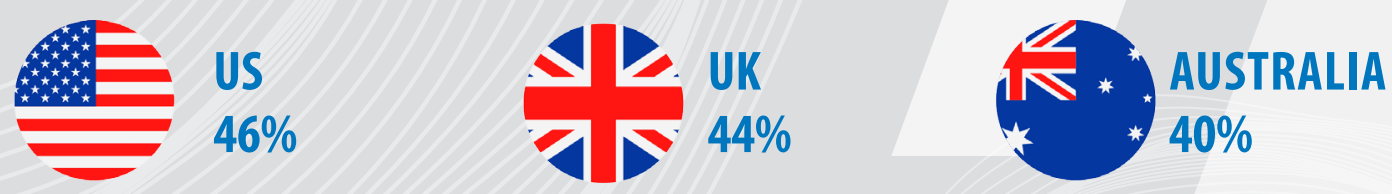

$56 \%$
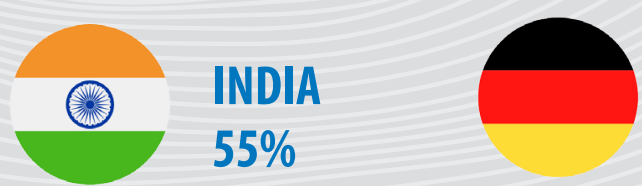

GERMANY $53 \%$

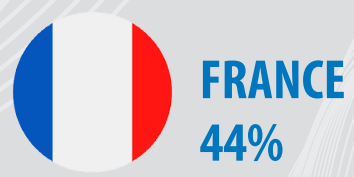




\section{A deeper look at Al maturity levels by sector}

The maturity index shows us that across all organizations, the evaluation and partial deployment stages dominate the Al journey. Organizations across all verticals continue to evaluate Al, as well as look inwardly at their own workflows and employee processes to better understand how and where Al could fit. Current spending will be, in part, on evaluation, proof of concept, prototypes, external support and expertise to help companies on their way. However, we also see that a fifth of organizations are being aggressive in their investment in and adoption of $\mathrm{Al}$ technologies. These "rising stars" represent the trailblazers at the infancy of modern Al technology, potentially setting themselves up for greater success as Al becomes more widely adopted and more developed.

Figure 5: Average survey score by industry, all respondents $(1,600)$

Pharmaceuticals/life sciences

Automotive and aerospace

Telecoms

Energy, oil/gas and utilities

Manufacturing

Fast moving consumer goods

Healthcare

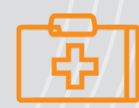

Financial services

Retail
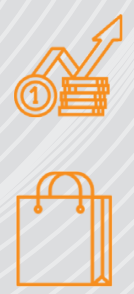

Public sector

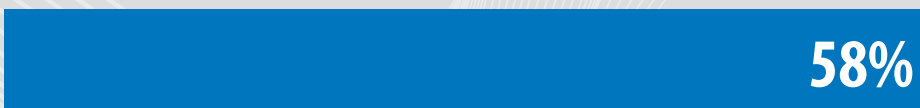

$54 \%$

$52 \%$

$51 \%$

\section{$50 \%$}

\section{$50 \%$}

\section{$50 \%$}

\section{$47 \%$}

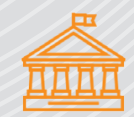




\section{THE AI ETHICS DEBATE}

\section{Delivering on the promise of AI}

With the vast majority somewhere along the journey of Al adoption, respondents from organizations that have or are planning to deploy Al technologies, report multiple drivers behind their decision. These include a desire to increase efficiency through automating IT (59\%) or business processes (55\%) or boosting employee productivity (56\%). Financial goals are also key factors, with a similar number looking to save costs (55\%) or increase revenues (53\%).

A highly positive picture emerges when comparing initial adoption drivers against actual benefits that many organizations have experienced. The message is that Al can deliver on what it promises. Significant numbers of decision-makers report that their organizations have benefited from the automation of processes (46\%), cost savings (44\%), increased productivity (44\%) and an increase in revenue (39\%).

Al can demonstrate its value to the business internally, but it does not end there, and that means good news for the customer as well. Almost all (97\%) decision-makers feel that there are customer benefits to be had. They hope that Al can assist customers in many ways, particularly in the creation of new products, services and business models (55\%). Also in giving faster access to existing ones (55\%). In a world where customer demands become ever more instant and specific, many feel Al can help with the quicker resolution of problems (50\%) and greater personalization (42\%).

Furthermore, by 2020 almost all respondents believe Al can generate a significant ROI impact through both an expected 39\% boost to revenues on average and an anticipated $37 \%$ reduction in costs.

\section{Breaking down the barriers}

The use of Al presents an extraordinary set of hurdles. Organizations using it to some extent find themselves struggling to get the most out of it - only $10 \%$ of respondents' organizations are fully maximizing the current available benefits of $\mathrm{Al}$. 


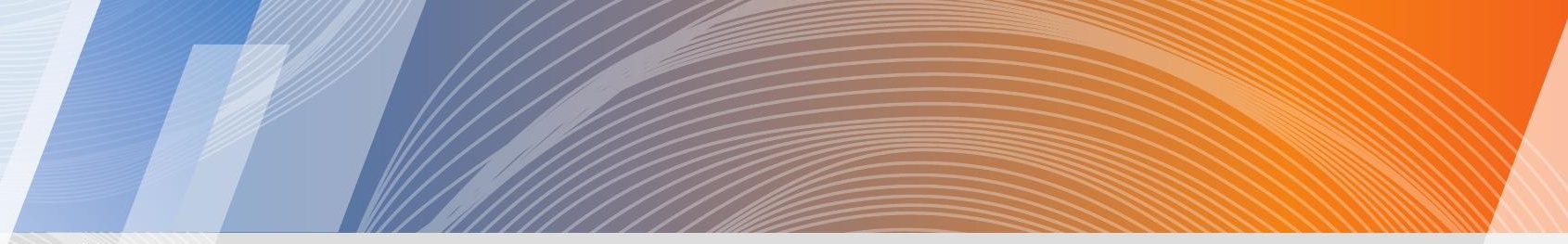

Figure 6: "Which of these barriers does your organization face in adopting Al technologies?", all respondents $(1,600)$

Employee fear of change

Lack of in-house skills to implement and manage

Lack of knowledge about where Al can assist

Concerns about handing over control

Cultural acceptance

Senior management resistance

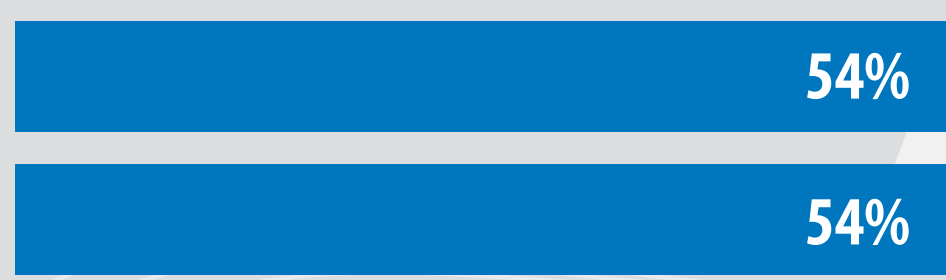

$49 \%$

\section{$47 \%$}

\section{$47 \%$}

\section{$37 \%$}

As one might expect, given Al's broad potential use, there are a wide range of barriers. Among the most commonly highlighted center around the employee fear of change (54\%) and cultural acceptance (47\%). Many also feel that a lack of in-house skills to manage Al (54\%) is a concern. Perhaps a symptom of this is that many report a lack of knowledge in their organizations about exactly where Al can assist (49\%).

These issues can be addressed by increasing awareness of $\mathrm{Al}$ in organizations, and it is encouraging that only the minority report senior management resistance (37\%) as a barrier — for the Al dream to become a reality, organizations require effective leadership from above. As Al adoption spreads, the industries in which organizations operate are likely to be impacted. Around four in 10 (39\%) decision-makers report that their industry has already faced disruption by Al, and over seven in 10 (71\%) either have been or expect to be at some point.
The call to action is clear — organizations must start to consider the use of Al not just as a means to differentiate, but simply to keep up.

\section{The inevitable impact of Al}

Ethics and successful Al adoption are a tricky balancing act — while the majority of respondents believe that their organization's future growth is dependent on large-scale Al adoption (64\%), over half (53\%) feel that ethical concerns significantly stop Al being as effective as it can be. Almost two-thirds (62\%) believe that stringent ethical standards are needed to ensure the success of Al deployments.

However, with the majority (71\%) of respondents believing that $\mathrm{Al}$ is "inevitable", it is concerning that just over a third (36\%) believe that their organizations have completely considered the ethical issues relating to the use of $\mathrm{Al}$. 


\section{Employees - reduce, redeploy, upskill?}

It is expected that the benefits of Al will eventually spread beyond the organization - the majority feel it can deliver positive societal (70\%) and economic (76\%) change. In anticipation of such benefits, it is interesting to note that a significant minority of respondents' organizations are even willing to endure short-term pain in the form of sacrificing employee (39\%) or customer (35\%) satisfaction in order to achieve the longer-term gain that Al promises. However, the concerns of these key stakeholder groups cannot be swept under the carpet, particularly when 90\% of respondents believe that employees have concerns about $\mathrm{Al}$ and $88 \%$ believe the same for customers.

When it comes to employee concerns, a third or more decision-makers consider issues around data safety (43\%) and an increased impact on privacy (34\%) to be among the chief areas. Almost three in 10 (28\%) believe that Al's impact will go beyond day-to-day concerns and will affect their employees' human dignity. With employees tasked with the management and use of $\mathrm{Al}$, these are fears that cannot be ignored.

A range of concerns are also highlighted in relation to respondents' organization's customers - the most likely being a lack of understanding about Al's use (41\%). Similar numbers also see a mistrust of the technology by consumers (38\%).
With employee concerns faced by many, this should be a primary consideration for organizations when developing their Al plans.

With that in mind, it is highly encouraging to see respondents' organizations either currently or planning to undertake activities to boost awareness. Over eight in 10 report that their organization is giving, or planning to give, teams freedom to experiment with new technologies (83\%) or training employees about the benefits of $\mathrm{Al}$ (85\%). Most positively of all perhaps, is that although three-quarters (75\%) are currently or planning to replace workforce resources with Al technology, the vast majority (80\%) of respondents' organizations will retrain or redeploy displaced employees. This is an optimistic sign that fears may be misplaced and that Al deployment and worker redundancy do not necessarily go hand in hand.

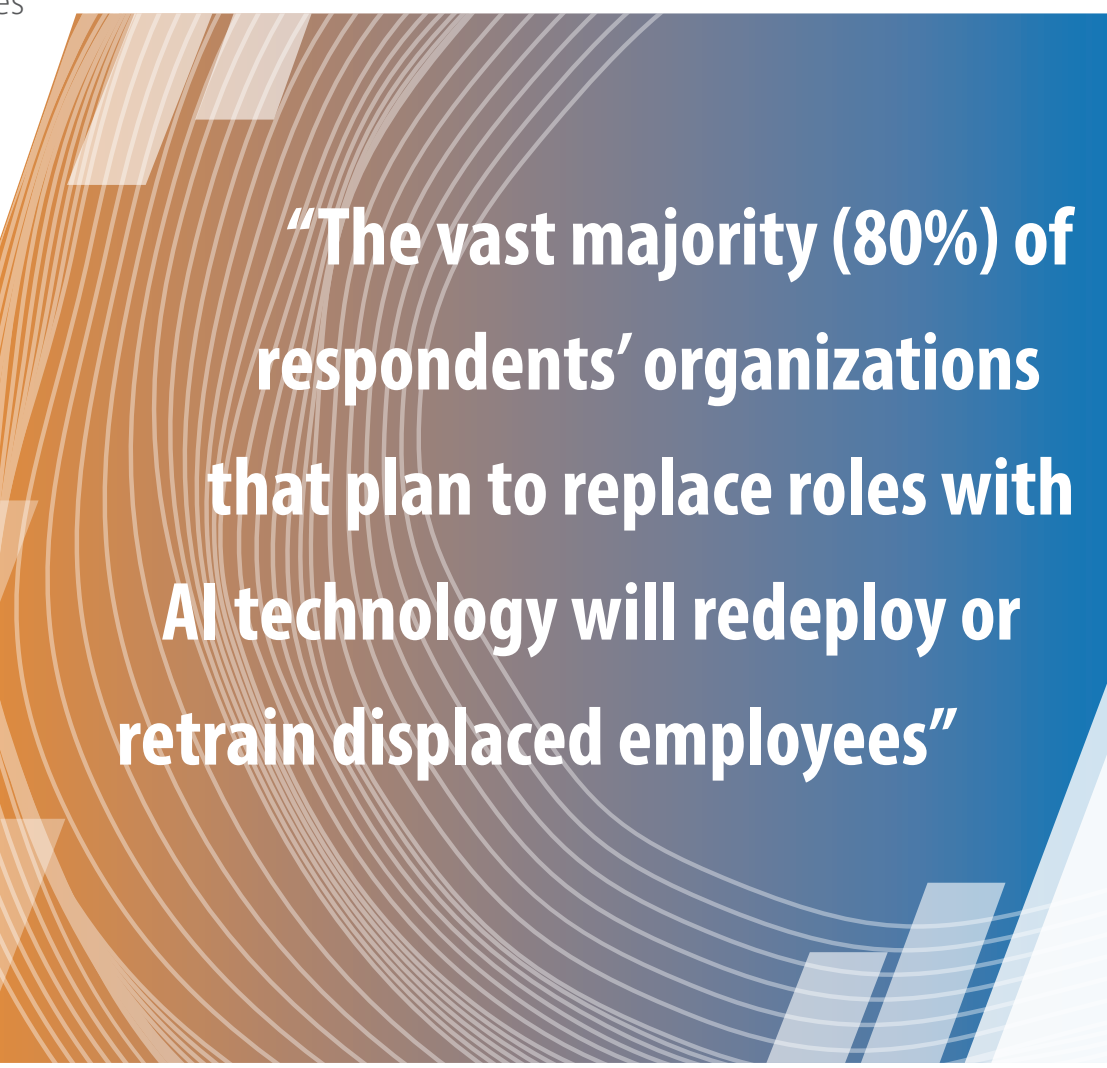




\section{Mapping out the future of Al}

Looking to the future, with all the benefits and challenges of Al adoption, there are a variety of improvement areas that are highlighted. Among the most common are improving Al's time to implement (44\%) and ease of use (43\%). For organizations to harness the benefits, they need to act as quickly as possible to set progress in motion. As we have already seen, many will look to third-party specialists or focus on training internal users to boost knowledge and awareness. With many already behind their competitors when it comes to Al and with industry disruption rising, the case becomes more and more pressing.

The skills of employees entrusted to lead the Al journey are critical to success. However, over four in 10 do not feel that they have the necessary development (42\%), security (42\%) or implementation (43\%) skills required for Al use. In addition, despite the concerns of employees and customers, only a minority of decision-makers believe that their organizations have Al-related training (47\%) or
Al-related customer facing (37\%) skills. Such gaps threaten to derail many organizations before they have even begun to use Al, putting success at risk. In light of this, the study offers encouragement in that many organizations plan to invest in Al training for employees in the future.

In a world of Al, what are the key skills that organizations will demand of future generations in the workforce? What is clear is that the level and sophistication of skills will rise, with decision-makers believing active learning (58\%), complex problem-solving (53\%) and critical thinking (46\%) to be key. Creativity (46\%) and logical reasoning (43\%) also come into play, highlighting a growing need for employees who can learn quickly, think on their feet and overcome problems efficiently to succeed in an Aldriven environment. In order to reach this level, the most important academic subjects that decision-makers see as focus areas for future generations are computer sciences (72\%), business and management (47\%) and mathematics (45\%).

Figure 7: "Which of the below skills do you believe your organization's employees have when it comes to implementing and using AI?", all respondents $(1,600)$

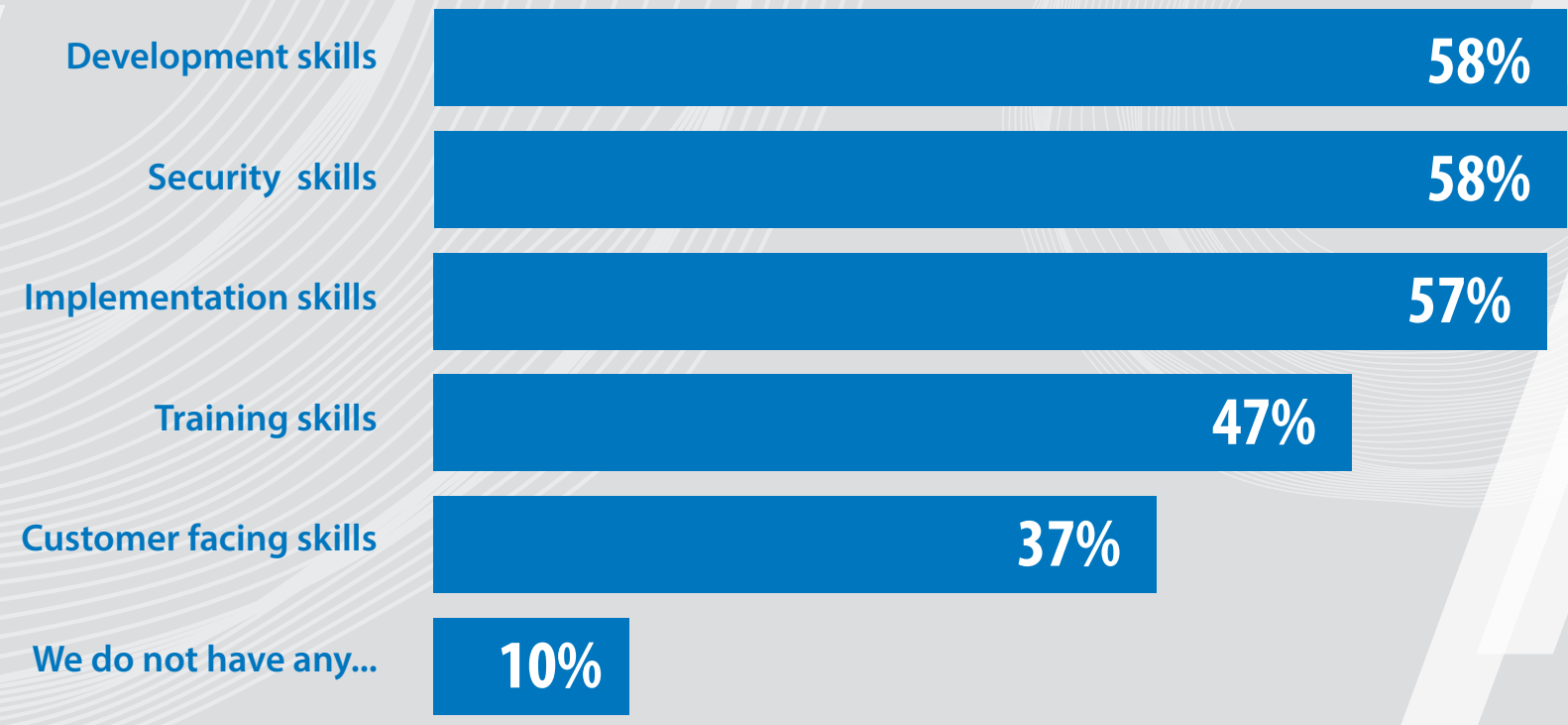




\section{CONCLUSION}

As the vast majority of decision-makers believe, $\mathrm{Al}$ is inevitable. Some organizations already find themselves actively exploring how the technology can work for them, while many remain focused on planning their approach. What is clear, however, is that the successful use of Al requires balance: greater automation versus employee engagement and customer satisfaction versus changing business models. The goal is to harness the vast array of possible rewards while also minimizing the many potential risks.

Driven by the significance of the potential benefits, Al adoption continues to spread more widely throughout organizations and begins to touch and impact more employees and customers.

However, ethics are a significant factor. The key responsibilities and challenges here for organizations are to properly address ethical concerns as they try to maximize potential. Not only for Al technology, but also as they seek to amplify the potential of the human workforce. This is not an easy task, but remains one that offers significant benefits for the organization, with $\mathrm{Al}$ and the workforce working side-by-side, as Al supports the people in the organization to do more, be more creative and to deliver greater value for the business. Many could improve their consideration of ethical issues. Those that fail to do so are at risk of being left behind by more Almature organizations that can balance the often opposing competing forces of doing well and doing right.

So, with many organizations still a number of years away from reaching Al maturity, what can they learn from those Al visionaries who are leading the way?

The key factor in organizations that are more mature in their use of $\mathrm{Al}$ is that employee resources are being effectively used to the benefit of Al implementation and not simply sidelined by technology. Organizations that can retrain or redeploy employee resources instead of simply making redundancies stand to benefit from increased skills and greater motivation to help further explore what Al can bring. Organizations have high expectations of the future generation and the skills it should offer - once these employees are on-board, it is down to their organizations to help further nurture and foster talent in an increasingly Al-filled world.

A holistic view to Al adoption is also fundamental those that look to apply an array of technologies across multiple areas will position themselves to benefit the most from the potential synergies that Al can offer — not 
least the anticipated significant $\mathrm{ROI}$ benefits in the form of revenue and cost. Strong established links between Al adoption and overall business strategy are key features of organizations that are true Al visionaries. Such an approach helps to consider and align the needs of employees and customers, ensuring that their trust and buy-in is achieved.

Overall, the adoption and use of Al technologies offer an exciting leap forward for many organizations, but careful consideration must be placed on the impact of doing so to ensure that employees and customers are actively engaged along the journey.

\section{Scope of research/methodology}

Infosys commissioned independent technology market research specialist Vanson Bourne to undertake the research upon which this report is based. 1,600 IT and business decision-makers were interviewed in November 2016. All came from organizations of more than 1,000 employees, with $\$ 500 \mathrm{M}$ or more annual revenue and from a range of sectors.
The research was carried out across seven countries with interviews split accordingly:

\begin{tabular}{|c|c|}
\hline Country & \multicolumn{2}{|c|}{ Number of interviews } \\
\hline US & 400 \\
\hline UK & 200 \\
\hline France & 200 \\
\hline Germany & 200 \\
\hline Australia & 200 \\
\hline China & 200 \\
\hline India & 200 \\
\hline
\end{tabular}

The majority of interviews were conducted using online interviewing with a small number of telephone interviews. All were undertaken using a rigorous multi-level screening process to ensure that only suitable candidates were given the opportunity to participate. Unless otherwise indicated, the results discussed are based on the total sample. 


\section{ABOUT INFOSYYS}

Infosys is a global leader in technology

services and consulting. We enable clients in

more than 50 countries to create and execute

strategies for their digital transformation.

From engineering to application development,

knowledge management and business process

management, we help our clients find the right

problems to solve, and to solve these effectively.

Our team of 200,000+ innovators, across the

globe, is differentiated by the imagination,

knowledge and experience, across industries and

technologies, that we bring to every project we

undertake.

Visit www.infosys.com to see how Infosys

(NYSE: INFY) can help your enterprise thrive in

the digital age.

\section{Infosys}

\section{FOR MORE INFORMATION, CONTACT ASKUS@INFOSYS.COM}

@ 2017 Infosys Limited, Bengaluru, India. All Rights Reserved. Infosys and its affliates believe that the information in this document is accurate as of its publication date; Such information is subject to change without notice. Infosys acknowledges the proprietary rights of other companies to the trademarks, product names and such other intellectual property rights mentioned in this document. Except as expressly permitted, neither this document nor any part of it may be reproduced, stored in a retrieval system, or transmitted in any form, or by any means electronic, mechanical, printing, photocopying, recording or otherwise without the prior permission of Infosys Limited and/or any named intellectual property rights holders under this document. 

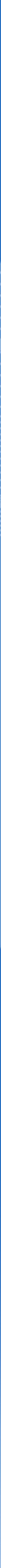